\title{
High expression of RELM- $\alpha$ correlates with poor prognosis and promotes angiogenesis in gastric cancer
}

\author{
PING CHEN $^{1}$, DESHOU ZHAO $^{2}$, WEIYI WANG ${ }^{1}$, YONGPING ZHANG ${ }^{1}$, \\ YAOZONG YUAN $^{3}$, LIFU WANG $^{3}$ and YUNLIN WU ${ }^{1}$ \\ ${ }^{1}$ Department of Gastroenterology, Ruijin Hospital North, Shanghai Jiaotong University School of Medicine, Shanghai 200025; \\ ${ }^{2}$ Department of Laboratory, Second Hospital Affiliated to Lanzhou University, Lanzhou, Gansu 746000; \\ ${ }^{3}$ Department of Gastroenterology, Ruijin Hospital, Shanghai Jiaotong University \\ School of Medicine, Shanghai 200025, P.R. China
}

Received December 23, 2014; Accepted March 2, 2015

DOI: 10.3892/or.2015.3943

\begin{abstract}
Accumulating evidence indicates that resistin-like molecule- $\alpha$ (RELM- $\alpha$ ) is involved in angiogenesis, while the clinical significance and the exact role of RELM- $\alpha$ in gastric cancer remain obscure. The aim of the present study was to evaluate the clinical significance of RELM- $\alpha$ in gastric cancer, and to investigate its effective mechanisms in order to identify a potential therapeutic target. The expression levels of RELM- $\alpha$ in 92 gastric cancer and adjacent normal tissues were investigated and the relationship between RELM- $\alpha$ expression and the clinicopathological characteristics was explored. To investigate the potential role of RELM- $\alpha$ in gastric cancer cell biological behavior, the cell proliferation, migration and invasion assays were conducted using two gastric cancer cell lines (SGC7901 and MKN45). We also assessed whether RELM- $\alpha$ gene silencing modulates angiogenesis using small interference RNA in cancer cell lines, and investigated its effect on nuclear factor $(\mathrm{NF})-\kappa \mathrm{B}$ activation and vascular endothelial growth factor (VEGF) and MMP-9 expression. Contrasting sharply with the strong RELM- $\alpha$-positive tumors, adjacent normal tissues and cell lines exhibited negative or weakly positive expression $(\mathrm{P}<0.01)$. High expression level of RELM- $\alpha$ was associated with advanced stage and tumor size $(\mathrm{P}<0.01)$. The silencing of RELM- $\alpha$ expression by Ad5/F35-siRNA treatment significantly inhibited cell migratory and invasive ability in SGC7901 and MKN45 gastric cancer cells compared with the control and Ad5/F35 vector-transfected cell lines $(\mathrm{P}<0.01)$. However, the silencing of RELM- $\alpha$ expression also significantly blocked NF- $\kappa$ B activation and attenuated VEGF and MMP-9
\end{abstract}

Correspondence to: Professor Yunlin Wu or Dr Lifu Wang, Department of Gastroenterology, Ruijin Hospital North, Shanghai Jiaotong University School of Medicine, Shanghai 200025, P.R. China E-mail: wuyunlin2014@126.com

E-mail: lifuwang@sjtu.edu.cn

Key words: gastric cancer, RELM- $\alpha, \mathrm{NF}-\kappa \mathrm{B}$, angiogenesis, prognosis expression. The data demonstrated that RELM- $\alpha$ is a promising novel biomarker of angiogenesis in patients with gastric cancer. The study identified that the silencing of RELM- $\alpha$ expression may regulate the proliferation, invasion and migration of gastric cancer cells by targeting VEGF/MMP-9, and the mechanism involved tissue angiogenesis via the $\mathrm{NF}-\kappa \mathrm{B}$ signaling pathway.

\section{Introduction}

Gastric cancer is a disease with one of the poorest prognoses, and is the second leading cause of tumor-related mortality worldwide. The 5-year overall survival is $25 \%$ or less, particularly in the USA, Europe and China $(1,2)$. Every year, 1 million new cases of gastric cancer are diagnosed and 700,000 individuals succumb to this disease worldwide (3). Most patients with gastric cancer are diagnosed with advanced gastric cancer, and the overall survival rate remains poor. There is a need for new prognostic tumor markers that provide more effective therapeutic targets for gastric cancer.

Resistin-like molecule (RELM)- $\alpha$ belongs to the RELM family which are potent innate immune-modulating molecules which are implicated in Th2-associated mucosal immune responses (4). RELM- $\alpha$ was originally identified in inflammatory zones in an experimental allergic airway disease model and was therefore also termed found in inflammatory zone 1 (FIZZ1) $(5,6)$. Moreover, related studies found that RELM- $\alpha$ is a hallmark signature gene of activated macrophages. RELM- $\alpha$ expression is tightly regulated by IL-13, IL-4 and signal transducer and activator of transcription protein signaling pathway (7). RELM- $\alpha$ also has a key functions in fibrosis in the setting of experimental asthma (8). Notably, RELM- $\alpha$ was identified in the gastrointestinal tract and is strongly linked with the induction of Th2 immune responses and mucosal immunity, involving inflammatory bowel disease (9). Accumulating the evidence also indicates that RELM- $\alpha$ is involved in the angiogenesis of endothelial cells and induces vascular remodeling (10). Yet, RELM- $\alpha$ expression in gastric cancer and its correlation with gastric cancer clinicopathological characteristics remain unclear.

In the present study, we first examined RELM- $\alpha$ expression in 92 paired cases of gastric cancer and adjacent non-cancerous 
mucosa tissues and in SGC7901 and MKN45 gastric cancer cell lines to investigate the relevance of RELM- $\alpha$ expression in gastric cancer and its functional mechanism. In addition, an in vitro study was performed to observe the silencing effect of RELM- $\alpha$ on gastric cancer cells, to investigated its effective mechanism in order to determine its use as a potential therapeutic target.

\section{Materials and methods}

Patients and specimens. Ninety-two cases of gastric cancer and adjacent non-cancerous tissues were collected at Ruijin Hospital and Ruijin Hospital North, Shanghai Jiaotong University School of Medicine from April 2007 to February 2013. Tissue samples for diagnostic purposes were obtained with the consent of each patient. All tumor specimens and corresponding adjacent non-cancerous tissues were fixed in $10 \%$ buffered formalin, embedded in paraffin and then made into continuous $4-\mu \mathrm{m}$ tissue sections for examination. The study group consisted of 52 males and 40 females, aged 18-92 years, with an average age of $61 \pm 14$ years. Each specimen was analyzed by routine pathological analysis and was classified according to the pathological criteria published by the World Health Organization (4th edition) and the tumor-node-metastasis (TNM) staging system of the American Joint Committee on Cancer Staging Manual (7th edition) and the Japanese Gastric Cancer Association Guidelines (3rd edition). None of the gastric cancer patients had synchronous cancers or previous gastrointestinal diseases, nor had undergone abdominal surgery, chemotherapy or radiotherapy prior to specimen collection. The present study was performed with pre-approval from the ethics committees of the participating hospitals.

Immunohistochemistry. Gastric cancer tissue paraffin sections were placed in citrate buffer $(\mathrm{pH}$ 6.0) for antigen retrieval. The negative control antibody was replaced by phosphatebuffered saline (PBS). The procedure was in accordance with the SP detection instructions (Maixin Co., Fujian, China). Paraffin sections (4- $\mu \mathrm{m})$ were used for histological staining. The diluted density of rabbit anti-human RELM- $\alpha$, vascular endothelial growth factor (VEGF), CD34 antibody (Santa Cruz Biotechnology, Santa Cruz, CA, USA) as the primary antibodies was 1:50. Thereafter, each section was incubated with the horseradish peroxidase (HRP)-labeled anti-rabbit IgG antibody (Maixin Co.). The immunostained specimens were assessed by two independent observers without prior knowledge of the clinicopathological characteristics.

The RELM- $\alpha$ or VEGF protein positive expression was mainly localized in the cytoplasm of gastric cancer tissue. The staining intensity score was 0 (negative), 1 (weak), 2 (medium) and 3 (strong). The integral of the rate of positive cells was 0 (0\%), 1 (1-25\%), 2 (26-50\%), 3 (51-75\%) and 4 (76-100\%). The proportional score and the intensity score were then added to obtain a total score. A score $\geq 3$ was considered to indicate positive expression.

Microvessel density (MVD) was assessed according to the criteria proposed by Weidner et al (11); the brownish cytoplasmic staining of vascular endothelial cells with CD34 antibody was considered as positive. The microvessels were counted according to the number of single endothelial cells or endothelial cell clusters showing brownish yellow granules in the cytoplasm. The sections were observed first under low-power magnification (x40), and then the most dense area of microvessel sections was selected under high-power magnification ( $x 400$; the surface area of every vision field being $0.785 \mathrm{~mm}^{2}$ ). The number of microvessels in three vision fields was counted and averaged as MVD of the given specimen.

In vitro

Cell culture. Two gastric cancer cell lines (MKN45 and SGC7901) and the 293 cell line were obtained from Ruijin Hospital, Shanghai Jiaotong University School of Medicine. Cells were cultured in RPMI-1640 medium supplemented with $10 \%$ fetal bovine serum (FBS) (Gibco-BRL, Gaithersburg, MD, USA) and incubated in $5 \% \mathrm{CO}_{2}$ at $37^{\circ} \mathrm{C}$ in $95 \%$ humidity.

Construction of RELM- $\alpha$-siRNA. The specific silencing of the human RELM- $\alpha$ gene expression was achieved by the siRNA technique.

The study used replication defective adenovirus serotype 5/F35 (Ad5/F35) as the vector. Ad5/F35-RELM- $\alpha$-siRNA was constructed by Hongming Bio. (Shanghai, China) using a previously described method (12). RELM- $\alpha$-siRNA was chemically synthesized, and subcloned into the PDC316-MCMV-EGFP transfer plasmid (Mierobix Biosystems Co., Mississauga, ON, Canada). This plasmid was cotransfected into 293 cells, along with a fragment of the plasmid containing the Ad5/F35 adenoviral vector (Bengyuanzhengyang Bio., Beijing, China). Additionally, an Ad5/F35 containing an empty expression cassette was constructed for use as a control (Ad5/F35-vector). All of the viral constructs were similar with the exception of the trans-gene, and the production and purification procedures were identical. The SGC7901 and MKN45 cells at 50-60\% confluency in a total volume of $500 \mathrm{ml} /$ well growth medium, were randomly allocated into 3 groups: cells treated with PBS served as control cells; cells treated with Ad5/F35-RELM- $\alpha$ siRNA at a multiplicity of infection (MOI) of 10; and cells treated with the Ad5/F35-vector (MOI of 5) for $24 \mathrm{~h}$ for further examination.

RELM- $\alpha$ expression in cells. Total RNA was isolated from the cells using TRIzol reagent kits (Gibco-BRL, Rockville, MD, USA). The cDNA obtained from this reaction was mixed with PCR buffer, $\mathrm{MgCl}_{2}$, dNTPs, Taq DNA polymerase and human RELM- $\alpha$ gene-specific primers [the primer sequences of RELM- $\alpha$ : forward primer, 5'-GCT GGG ATG ACT GCT ACT GG-3' and reverse primer, 5'-AAG CGG GGT TAA TGG GCA AT-3' (synthesis by Sangon Biotech Co., Shanghai, China)] and amplified in an automated thermal cycler (BioRad MJ Mini; Bio-Rad Laboratories, Inc., Hercules, CA, USA). The conditions of RT-PCR were as follows: 1 cycle for $5 \mathrm{~min}$ at $95^{\circ} \mathrm{C}, 35$ cycles for $45 \mathrm{sec}$ at $94^{\circ} \mathrm{C}$, for $45 \mathrm{sec}$ at $55^{\circ} \mathrm{C}$, for $1 \mathrm{~min}$ at $72^{\circ} \mathrm{C}$, and 1 cycle for $10 \mathrm{~min}$ at $72^{\circ} \mathrm{C}$. The PCR products were separated by electrophoresis on $1.2 \%$ agarose gels and stained with ethidium bromide. The densities of the cDNA bands were analyzed by scanning densitometry using GelDoc 2000 software (Bio-Rad Laboratories, Inc.). The band densities were normalized to GAPDH (the primer sequence 
of GAPDH: forward primer, 5'-GG C TGAGAA CGG GAA GCT TGT C-3' and reverse primer, 5'-CAGCCT TCT CCA TGG TGG TGA AGA-3'; synthesis by Sangon Biotech Co.) band densities, and the results are expressed as ratios.

Cell viability assay. The effect of RELM- $\alpha$ silencing on gastric cancer cell viability was monitored using the 3-(4,5-dimethylthiazolyl-2)-2,5-diphenyltetrazolium bromide (MTT) (Sigma, St. Louis, MO, USA) colorimetric assay. In brief, a total of $2 \times 10^{3}$ cells were seeded in 96-well plates. After $24 \mathrm{~h}$, the cells were treated with Ad5/F35-RELM- $\alpha$-siRNA (MOI of 10) or transfected with the Ad5/F35 vector (MOI of 5). After $24 \mathrm{~h}$, $20 \mu 1 \mathrm{MTT}(5 \mathrm{mg} / \mathrm{ml})$ was added to each well. Four hours later, $100 \mu 1$ of dimethyl sulfoxide was added to each well after the medium was removed. Finally, the absorbance (A) was detected with an enzyme calibrator at $570 \mathrm{~nm}$, The cell viability $=(\mathrm{A}$ of study group/A of control group $) \times 100 \%$.

Scratch wound-healing assay. To measure cell motility, $4 \times 10^{5}$ cells were seeded into 6 -well plates. A central linear wound was created by scraping the cell monolayer with a $200-\mu 1$ sterile pipette tip. The media were carefully changed to remove any floating cells and cultured in $5 \% \mathrm{CO}_{2}$ at $37^{\circ} \mathrm{C}$. The migration of cells into the denuded areas in the scraped region was calculated at $48 \mathrm{~h}$, respectively. The wound at $0 \mathrm{~h}$ was considered $100 \%$ of the average gap.

Cell invasion assays. Invasion assays were performed using Transwell chambers (Corning Inc., Corning, NY, USA). Briefly, $2 \times 10^{6}$ cells/dish were seeded in a $10-\mathrm{cm}$ dish overnight in RPMI-1640 supplemented with 10\% FBS. Then, the medium was replaced with serum-free RPMI-1640 for $12 \mathrm{~h}$, and the cells were treated with or without Ad5/F35-RELM- $\alpha$-siRNA for $2 \mathrm{~h}$ in $10 \%$ FBS medium. The cells were collected and centrifuged at $500 \mathrm{xg}$ for $3 \mathrm{~min}$. The treated cells were seeded at a density of $1 \times 10^{5}$ cells/well in $10 \%$ FBS medium in the upper chamber. The lower chamber was filled with complete medium. The cells were allowed to migrate for $24 \mathrm{~h}$ at $37^{\circ} \mathrm{C}$. After the incubation, the cells that did not migrate, which remained on the top surface of the membrane, were removed with a cotton swab. The cell that migrated to the bottom side of the membrane were fixed in cold $75 \%$ methanol for $15 \mathrm{~min}$ and washed three times with PBS. Next, the cells were stained with Giemsa staining solution (Sigma) and then destained with PBS. The images were captured using an optical microscope (Nikon Co., Tokyo, Japan; magnification, x200), and invading cells were quantified by manual counting.

Western blot analysis. The levels of nuclear factor (NF)-кB p65, vascular endothelial growth factor (VEGF) and matrix metallopeptidase (MMP)-9 proteins were investigated in each group using western blotting. The cells were washed twice with PBS and then homogenized in RIPA buffer (Biyuntian Co., Shanghai, China). Following centrifugation at $12,000 \mathrm{x}$ g at $4^{\circ} \mathrm{C}$ for $10 \mathrm{~min}$, the supernatant was collected and stored at $80^{\circ} \mathrm{C}$. Protein concentration of each sample was determined by the BCA protein assay (Biyuntian Co.). Each sample was adjusted to a desired protein content of $40 \mu \mathrm{g}$, then denatured in loading buffer and separated by electrophoresis on $9 \%$ SDS polyacrylamide gel at $100 \mathrm{~V}$ for $120 \mathrm{~min}$. The separated proteins were transferred to polyvinylidene difluoride membranes using transfer buffer at $200 \mathrm{~mA}$ for $90 \mathrm{~min}$. The membranes were blocked with 5\% non-fat dry milk in Tris-buffered saline (TBS)-0.1\% Tween for $1 \mathrm{~h}$ at room temperature, washed three times for $10 \mathrm{~min}$ each in TBS-0.1\% Tween, and incubated with a primary antibody including NF- $\mathrm{B}$ p65, VEGF and MMP-9 (Santa Cruz Biotechnology) at a 1:1,000 dilution in TBS- $0.1 \%$ Tween overnight at $4^{\circ} \mathrm{C}$, respectively. After three 10 -min washings in TBS- $0.1 \%$ Tween, the membranes were incubated with a secondary antibody, HRP-conjugated rat antirabbit immunoglobulin G (Kangcheng Inc., Shanghai, China) for $1 \mathrm{~h}$ at room temperature. After washing, the membranes were detected using enhanced chemiluminescence methods (Amersham Biosciences, Piscataway, NJ, USA), and then were scanned for densitometry using Bio-Image Analysis System (Bio-Rad Laboratories, Inc.). For quantification, GAPDH was determined in a similar manner with the anti-GAPDH antibody (diluted to 1:1,000; Santa Cruz Biotechnology) as an endogenous control for other proteins.

Electrophoretic and mobility shift assay (EMSA). The activity of NF- $\kappa B$ of cells was examined by EMSA reagent kits (Pierce Chemical Co., Rockford, IL, USA). Nuclear extracts of cells were prepared from gastric cancer cells at $24 \mathrm{~h}$ after stimulation. The biotinylated double-stranded DNA probe sequence of NF- $\kappa \mathrm{B}$ was: sense, 5'-AGT TGA GGG GAC TTT CCC AGG C-3' and antisense, 3'-TCA ACT CCC CTG AAA GGG TCC G-5'.

A total of $5 \mu \mathrm{g}$ of nuclear extract was incubated with $5 \mathrm{ng}$ of biotinylated double-stranded oligonucleotides in $20 \mu \mathrm{l}$ of reaction mixture containing binding buffer, $2.5 \%$ glycerol, $0.05 \% \mathrm{NP}-40$ and $50 \mu \mathrm{g} / \mathrm{ml}$ poly(dI:dC) (Biyuntian Co.). After $20 \mathrm{~min}$ at room temperature, the reaction was terminated by addition of $2 \mu 1$ of $10 \mathrm{X}$ loading buffer. The mixture was run on $6 \%$ polyacrylamide gel. DNA was transferred to a membrane, followed by detection using streptavidin HRP-conjugated and chemiluminescence substrate from Pierce Chemical Co.

Statistical analysis. All statistical analyses were carried out using the SPSS software statistical package (version 13.0; SPSS, Inc., Chicago, IL, USA). The relationships between the differential expression of RELM- $\alpha$ and clinicopathological characteristics were evaluated by the $\chi^{2}$ test. The one-way analysis of variance (ANOVA) with Dunnett's multiple comparison tests was used for comparisons. A P-value $<0.05$ was considered to indicate a statistically significant result.

\section{Results}

RELM- $\alpha$ expression in the gastric cancer cases. Expression of RELM- $\alpha$ and VEGF showed a predominant localization to the cytoplasm or on the cell membrane in the tissue specimens. Specimens with positive expression are presented in Fig. 1. The results showed that positive expression of RELM- $\alpha$ was found in $64.1 \%$ (59/92) of the gastric cancer tissues compared with $16.3 \%$ (15/92) of the adjacent normal tissues.

Among the 92 cases of gastric cancer, 59 (64.1\%) cases had positive expression and $33(35.8 \%)$ cases had negative expression of RELM- $\alpha$; which showed a statistically significant 

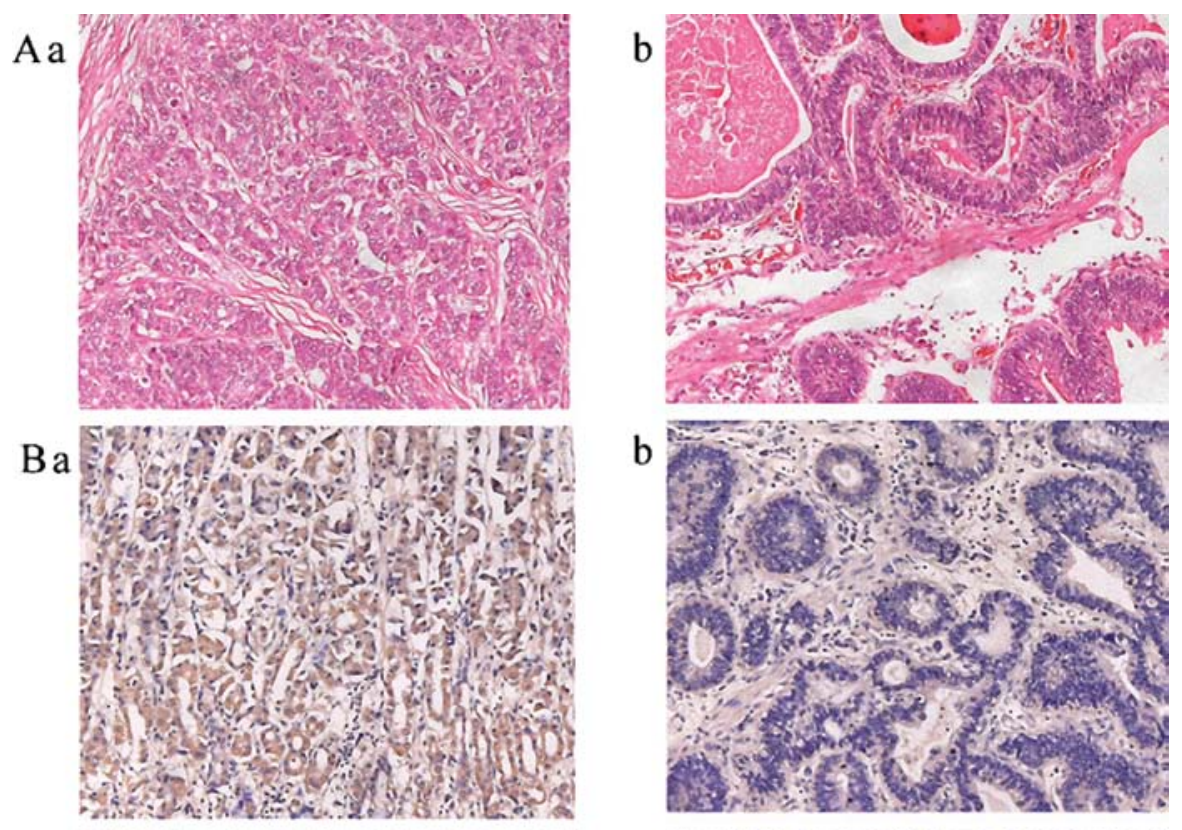

b
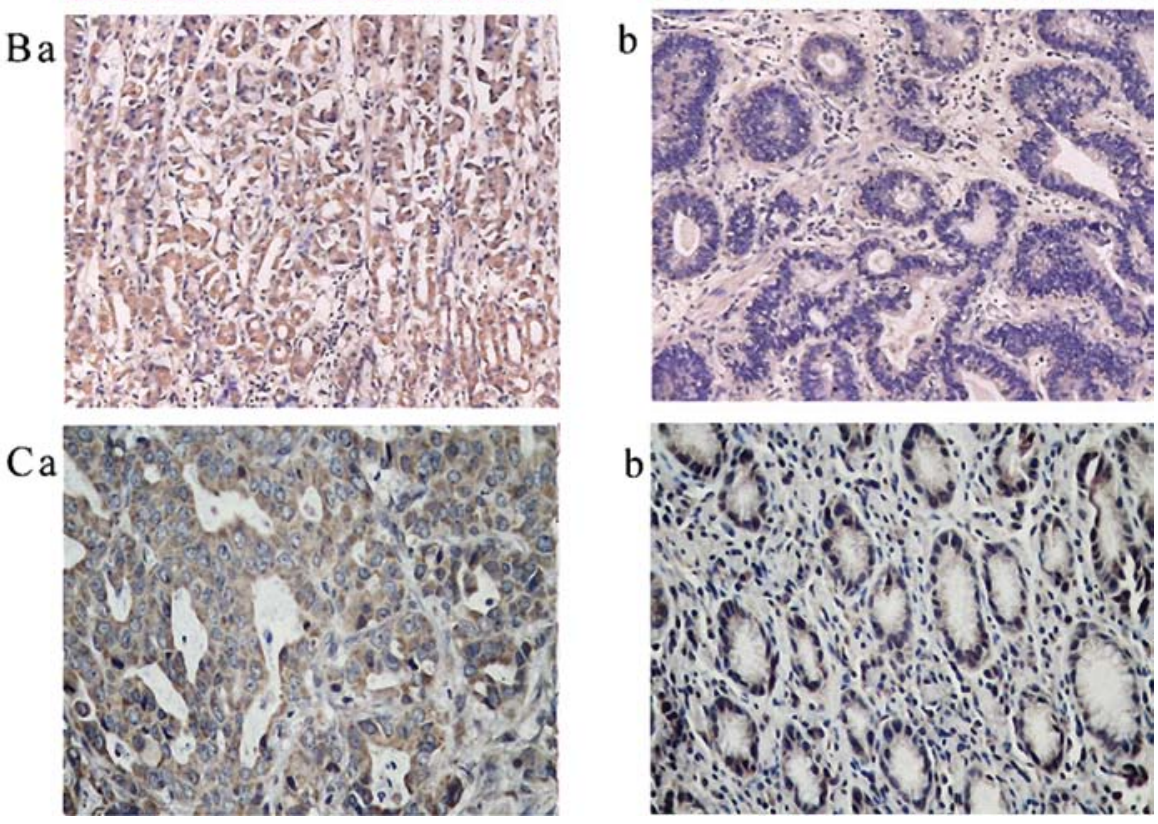

Figure 1. (A) Expression of RELM- $\alpha$ in (a) gastric cancer and (b) adjacent normal tissues are showed by hematoxylin and eosin staining (magnification, $x 200$ ). The expression of RELM- $\alpha$ and VEGF was investigated in gastric cancer and adjacent normal tissues by immunohistochemical method. (B-a) Strong RELM- $\alpha$ and (C-a) VEGF staining in invasive gastric cancers. Weak or negative (B-b) RELM- $\alpha$ and (C-b) VEGF staining in adjacent normal tissues of gastric cancer. Magnification, x400. RELM- $\alpha$, resistin-like molecule- $\alpha$; VEGF, vascular endothelial growth factor.
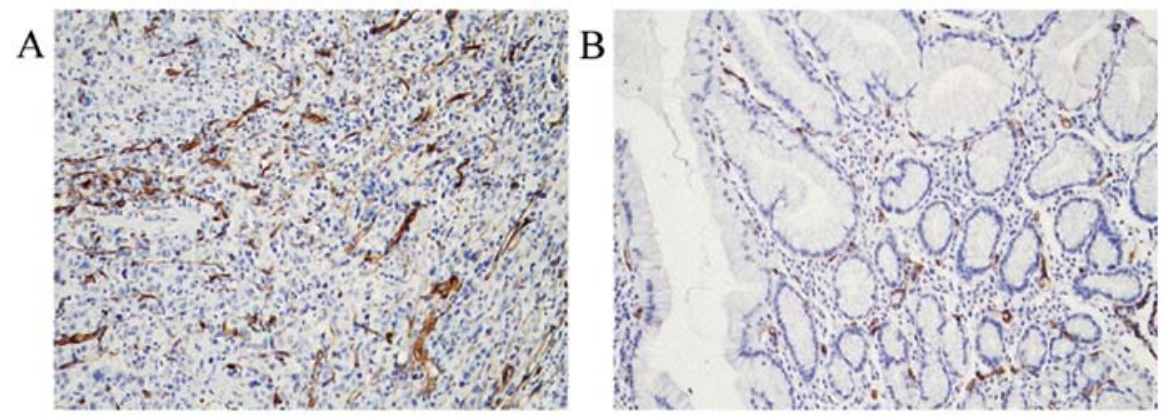

Figure 2. Expression of CD34 are investigated in (A) gastric cancer and (B) adjacent normal tissues by immunohistochemical method (magnification, x200).

difference $(\mathrm{P}<0.05)$. Moroever, among the gastric cancer cases, $77(83.6 \%)$ cases had positive expression and $15(16.4 \%)$ cases had negative expression of VEGF; which achieved a statistically significant difference $(\mathrm{P}<0.05)$.

Furthermore, the clinical relevance was confirmed by the observation that RELM- $\alpha$ expression was correlated with the prognosis in gastric cancer (Table I). Tumor stage and size were significantly associated with high expression of RELM- $\alpha$ protein $(\mathrm{P}<0.05)$. No correlation was observed between RELM- $\alpha$ protein expression and age, gender, degree of differentiation, and gross classification of tumors $(\mathrm{P}>0.05)$. In addition, the gastric cancer cases with positive expression of RELM- $\alpha$ and VEGF $(48 / 92,52.1 \%)$ were compared with those having negative expression of RELM- $\alpha$ and VEGF (4/92, $4.3 \%$ ), which showed a difference and thus may be correlated with each other (Table II).

As shown in Fig. 2, the MVD of tumors was determined by CD34 staining. The MVD value of the 92 gastric cancer specimens was $17.23 \pm 8.94$, while the MVD value in the 92 adjacent normal tissues was $6.58 \pm 2.32$, showing a statistically 
Table I. Relationship of RELM- $\alpha$ and VEGF expression with clinicopathological parameters in the patients with gastric cancer.

\begin{tabular}{|c|c|c|c|c|c|}
\hline & Total & $\begin{array}{c}\text { Positive expression } \\
\text { of RELM- } \alpha(\%, \text { cases })\end{array}$ & P-value & $\begin{array}{l}\text { Positive expression } \\
\text { of VEGF (\%, cases) }\end{array}$ & $\mathrm{P}$-value \\
\hline Total cases & 92 & & & & \\
\hline \multicolumn{6}{|l|}{ Age (years) } \\
\hline$\geq 55$ & 58 & $68.9(40 / 58)$ & \multirow[t]{2}{*}{0.207} & $81.0(47 / 58)$ & \multirow[t]{2}{*}{0.367} \\
\hline$<55$ & 34 & $55.8(19 / 34)$ & & $88.2(30 / 34)$ & \\
\hline \multicolumn{6}{|l|}{ Gender } \\
\hline Male & 52 & $55.7(29 / 52)$ & \multirow[t]{2}{*}{0.057} & $76.9(40 / 52)$ & \multirow[t]{2}{*}{0.607} \\
\hline Female & 40 & $75.0(30 / 40)$ & & $92.5(37 / 40)$ & \\
\hline \multicolumn{6}{|l|}{ Stage } \\
\hline $\mathrm{T} 2$ & 47 & $48.9(23 / 47)$ & \multirow[t]{2}{*}{0.020} & $80.8(38 / 47)$ & \multirow[t]{2}{*}{0.450} \\
\hline $\mathrm{T} 3, \mathrm{~T} 4$ & 45 & $86.8(36 / 45)$ & & $86.6(39 / 45)$ & \\
\hline \multicolumn{6}{|l|}{ Size (cm) } \\
\hline$\geq 5$ & 61 & $85.2(52 / 61)$ & \multirow[t]{2}{*}{0.000} & $90.1(55 / 61)$ & \multirow[t]{2}{*}{0.018} \\
\hline$<5$ & 31 & $22.5(7 / 31)$ & & $70.9(22 / 31)$ & \\
\hline \multicolumn{6}{|l|}{ Differentiation } \\
\hline Undifferentiated, poorly differentiated & 57 & $64.9(37 / 57)$ & \multirow[t]{2}{*}{0.842} & $87.7(50 / 57)$ & \multirow[t]{2}{*}{0.182} \\
\hline Moderately, well differentiated & 35 & $62.8(22 / 35)$ & & $77.1(27 / 35)$ & \\
\hline \multicolumn{6}{|l|}{ Gross classification } \\
\hline Early gastric cancer & 5 & $60.0(3 / 5)$ & \multirow[t]{4}{*}{0.250} & $80.0(4 / 5)$ & \multirow[t]{4}{*}{0.670} \\
\hline Borrmann I & 27 & $51.8(14 / 27)$ & & $88.8(24 / 27)$ & \\
\hline Borrmann II, III & 49 & $73.4(36 / 49)$ & & $83.6(41 / 49)$ & \\
\hline Borrmann IV & 11 & $54.5(6 / 11)$ & & $72.2(8 / 11)$ & \\
\hline
\end{tabular}

RELM- $\alpha$, resistin-like molecule- $\alpha$; VEGF, vascular endothelial growth factor.

Table II. Relationship between expression of RELM- $\alpha$ and VEGF with tumor stage, size and MVD in patients with gastric cancer.

\begin{tabular}{lcccrr}
\hline RELM- $\alpha$ & VEGF & Cases $(n=92)$ & MVD & Stage (T3, T4) \\
\hline+ & + & 48 & $23.77 \pm 6.33$ & 30 & 40 \\
+ & - & 11 & $14.15 \pm 5.24^{\mathrm{a}}$ & $2^{\mathrm{a}}$ & $5^{\mathrm{a}}$ \\
- & + & 29 & $8.39 \pm 4.18^{\mathrm{a}}$ & $1^{\mathrm{a}}$ & $3^{\mathrm{a}}$ \\
- & - & 4 & $7.80 \pm 2.28^{\mathrm{a}}$ & $3^{\mathrm{a}}$ & $1^{\mathrm{a}}$
\end{tabular}

${ }^{\mathrm{a}}$ vs. RELM- $\alpha\left(^{+}\right) / \mathrm{VEGF}\left(^{+}\right)$patients, $\mathrm{P}<0.01$. RELM- $\alpha$, resistin-like molecule- $\alpha$; VEGF, vascular endothelial growth factor; MVD, microvessel density.

significant difference between the gastric cancer and adjacent normal tissues $(\mathrm{P}<0.05)$.

In the 59 gastric cancer cases with positive RELM- $\alpha$ expression and the 33 cases with negative of RELM- $\alpha$ expression, the MVD was $22.23 \pm 6.79$ and $8.30 \pm 3.93$, respectively, which showed a statistically significant difference $(\mathrm{P}<0.05)$. Meanwhile, in the 77 gastric cancer cases with positive VEGF expression and the 15 cases with negative VEGF expression, the MVD was $19.12 \pm 8.49$ and $7.53 \pm 2.74$, respectively, which showed a statistically significant difference $(\mathrm{P}<0.05)$.

The tumor size, tumor stage and MVD value in the RELM- $\alpha$-positive/VEGF-positive gastric cancer patients were found to be higher when compared with these parameters in the RELM- $\alpha$-negative/VEGF-negative gastric cancer patients $(\mathrm{P}<0.01)$ (Table II).

In vitro

Effect of the silencing of RELM- $\alpha$ expression on gastric cancer cells. The levels of RELM- $\alpha$ expression in the SGC7901 and MKN45 cells were assessed by western blotting and RT-PCR assays methods (Fig. 3). The data showed that at $24 \mathrm{~h}$ following Ad5/F35-RELM- $\alpha$-siRNA treatment, RELM- $\alpha$ protein levels were decreased in the SGC7901 and MKN45 cells, yet not in the cells treated with the Ad5/F35-vector and the control cells $(\mathrm{P}<0.01)$ (Fig. 3A). Similar to the western blotting data, the SGC7901 and MKN45 cells with Ad5/F35-RELM- $\alpha$ - 

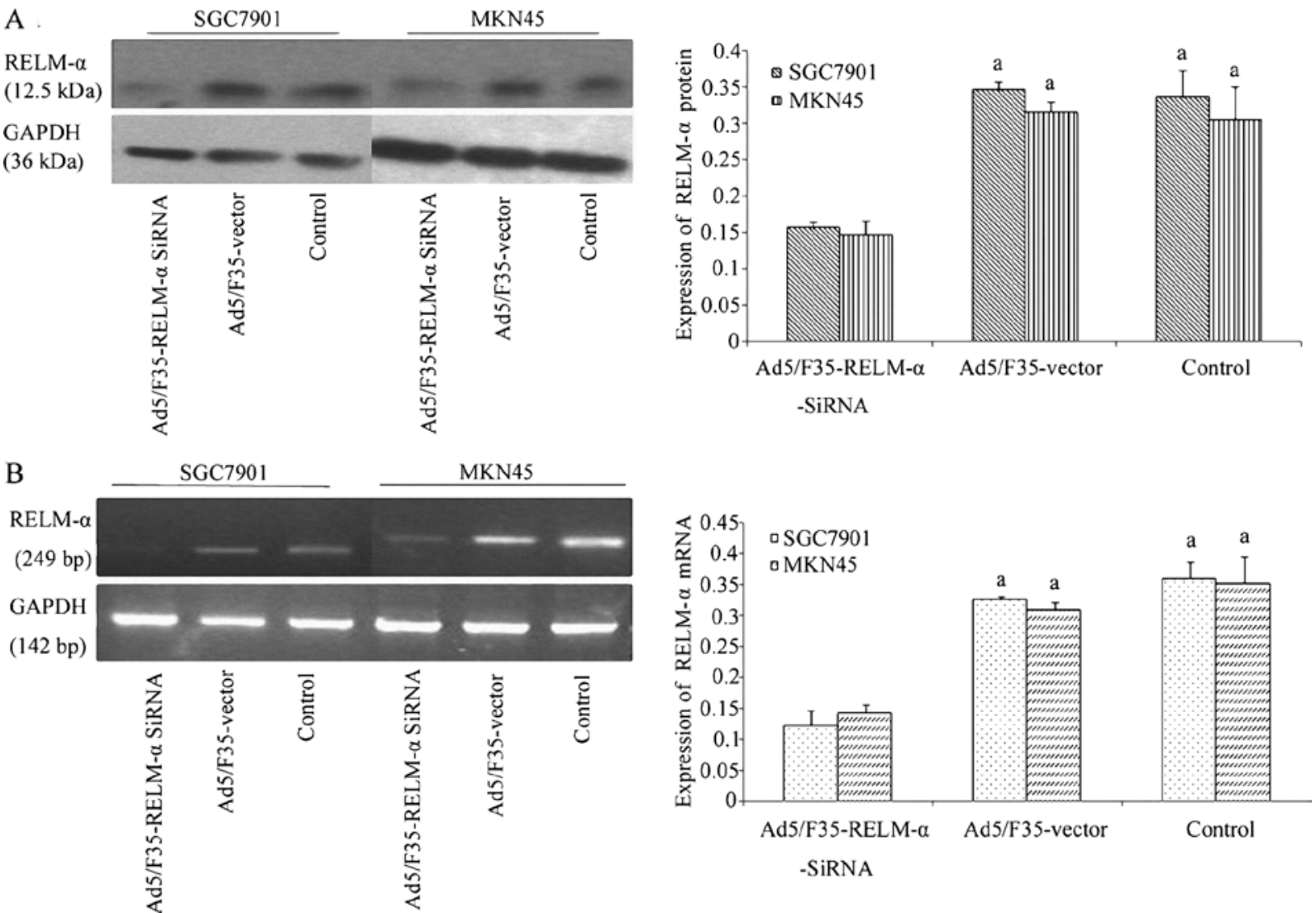

Figure 3. RELM- $\alpha$ expression was determined in gastric cancer cell lines SGC7901 and MKN45 in each treatment group. (A) Western blot analysis demonstrated that RELM- $\alpha$ expression was downregulated in the cells after infection with Ad5/F35-RELM- $\alpha$-siRNA at $24 \mathrm{~h}$. The control cells and the cells infected with Ad5/F35-vector showed high expression of RELM- $\alpha$ at $24 \mathrm{~h}$. (B) mRNA expression of RELM- $\alpha$ showed changes similar to the results of the western blot analysis. ${ }^{\text {P }}<0.01$ vs. the Ad5/F35-RELM- $\alpha$-siRNA-treated group. RELM- $\alpha$, resistin-like molecule- $\alpha$.

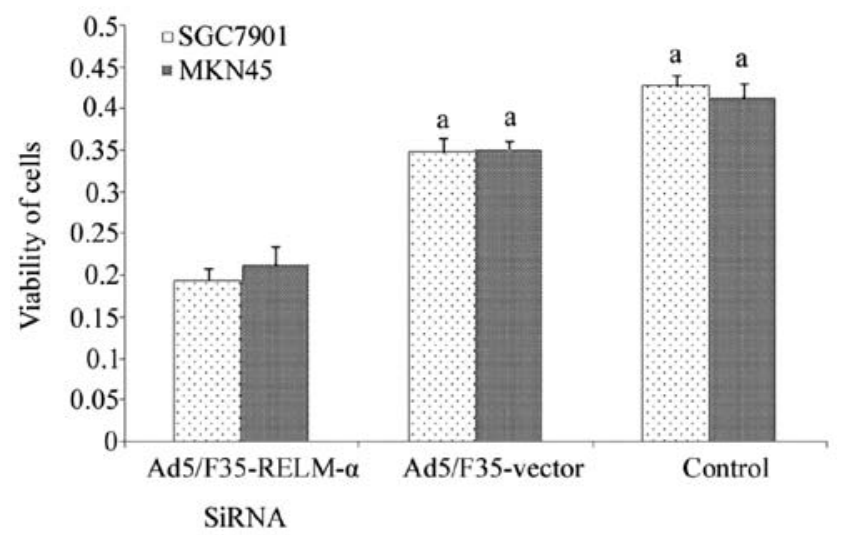

Figure 4. The viability of SGC7901 and MKN45 cells was evaluated by MTT assay in each cell group. ${ }^{a} \mathrm{P}<0.01$ vs. the Ad5/F35-RELM- $\alpha$-siRNA-treated group.

siRNA treatment expressed a lower level of RELM- $\alpha$ mRNA compared with the cells treated with the Ad5/F35 vector and the control cells $(\mathrm{P}<0.01)$ (Fig. 3B).

Effects of RELM- $\alpha$ silencing on cell proliferation. We aimed to assess whether RELM- $\alpha$ silencing suppressed the growth of gastric cancer cells (Fig. 4). The results showed that the percentage of viable cells following Ad5/F35-RELM- $\alpha$ siRNA treatment for $24 \mathrm{~h}$ was reduced in the two gastric cancer cell lines when compared with the control and Ad5/F35 vector-treated cells as determined by MTT assay $(\mathrm{P}<0.01)$.

Furthermore, to examine the effect of RELM- $\alpha$ silencing on cell motility, an in vitro scratch wound-healing assay was performed. The results indicated that the Ad5/F35-RELM$\alpha$-siRNA-treated cells significantly $(\mathrm{P}<0.01)$ exhibited slower repair of the scratched wound when compared with the control and the RELM- $\alpha$ vector-treated cells (Fig. 5). This result suggests that the silencing of RELM- $\alpha$ expression inhibited cell migration.

To further investigate the effect of RELM- $\alpha$ silencing on cell invasion, the invasive ability of the cells was examined using a Transwell chamber assay (Fig. 6). After incubation for $24 \mathrm{~h}$, the number of control and Ad5/F35 vector-treated cells which had invaded the polycarbonate membrane of the Matrigel chamber was 2 -fold higher than that of the Ad5/F35-RELM- $\alpha$-siRNA-treated group, respectively, which showed a statistically significant difference $(\mathrm{P}<0.01)$. These results provide evidences that RELM- $\alpha$ plays a role in enhancing the metastasis of gastric cancer cells.

The mechanism involved in RELM- $\alpha$ silencing in gastric cancer cells. To determine the effect of RELM- $\alpha$ on NF- $\kappa \mathrm{B}$ activation, NF- $\kappa \mathrm{B}-\mathrm{DNA}$ binding activity was determined in the different treated and control gastric cancer cells by EMSA. In Fig. 7, after treatment with Ad5/F35-RELM- $\alpha$-siRNA for 
SGC7901

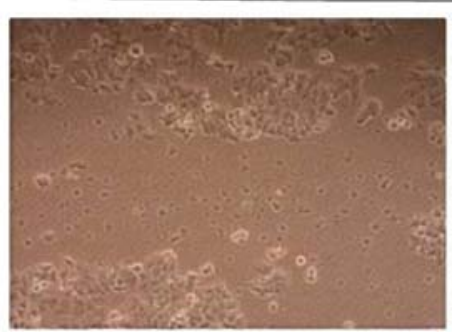

Ad5/F35-RELM- $\alpha$-SiRNA

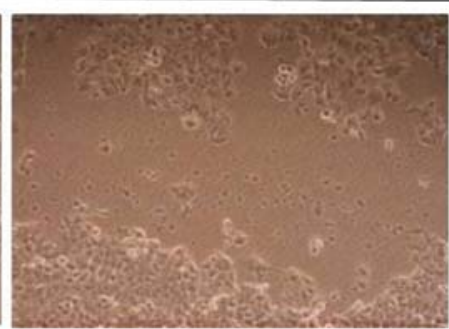

Ad5/F35-vector

MKN4S

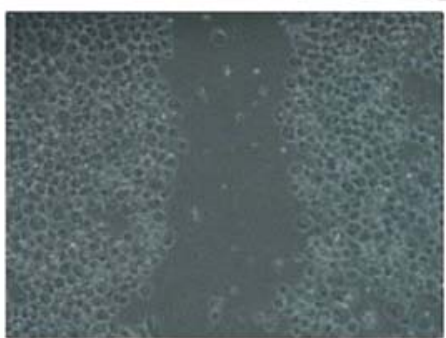

Ad5/F35-vector

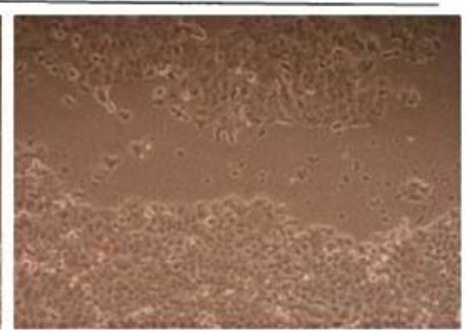

Control

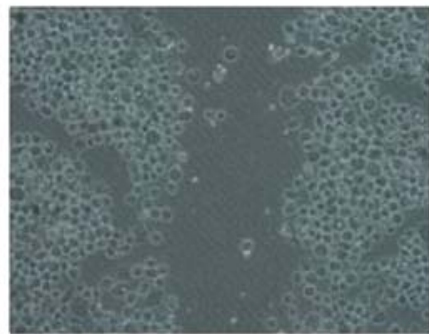

Ad5/F35-RELM- $\alpha$-SiRNA
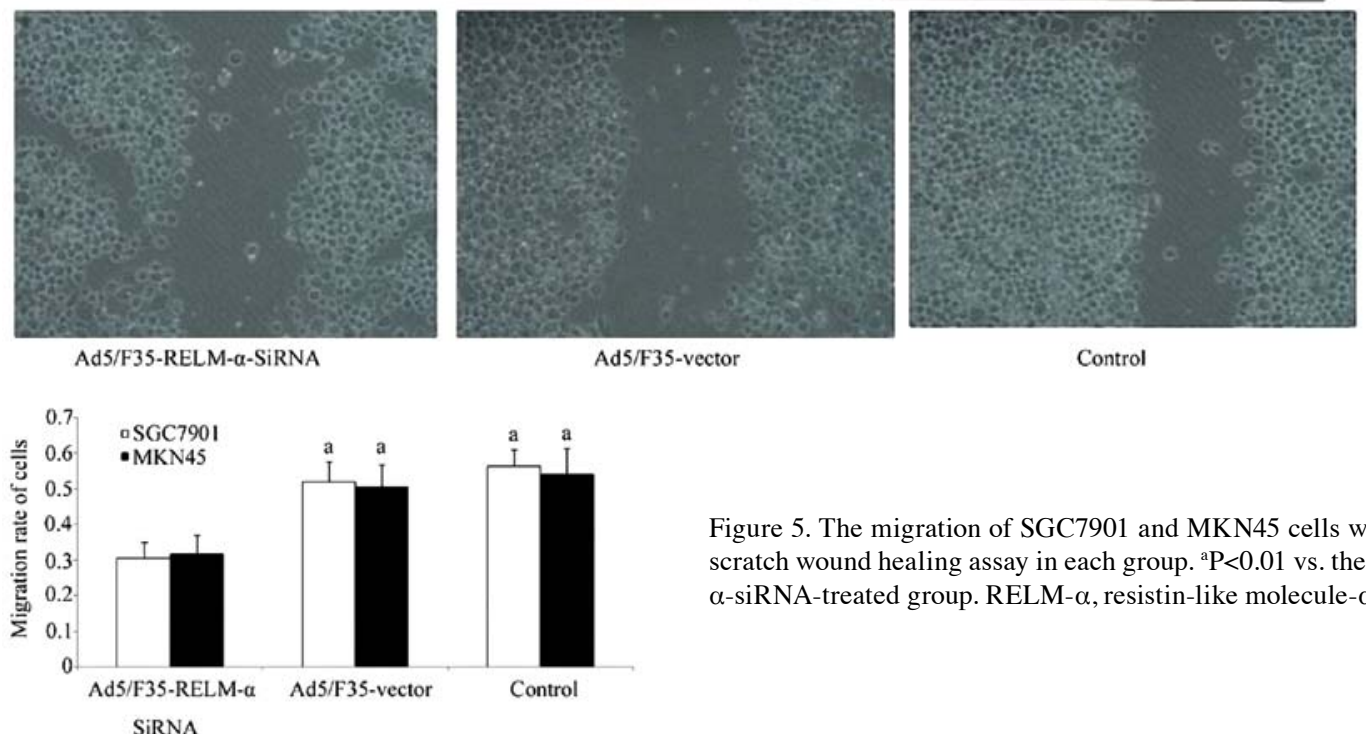

Control

Figure 5. The migration of SGC7901 and MKN45 cells was investigated by scratch wound healing assay in each group. ${ }^{a} \mathrm{P}<0.01$ vs. the Ad5/F35-RELM$\alpha$-siRNA-treated group. RELM- $\alpha$, resistin-like molecule- $\alpha$.

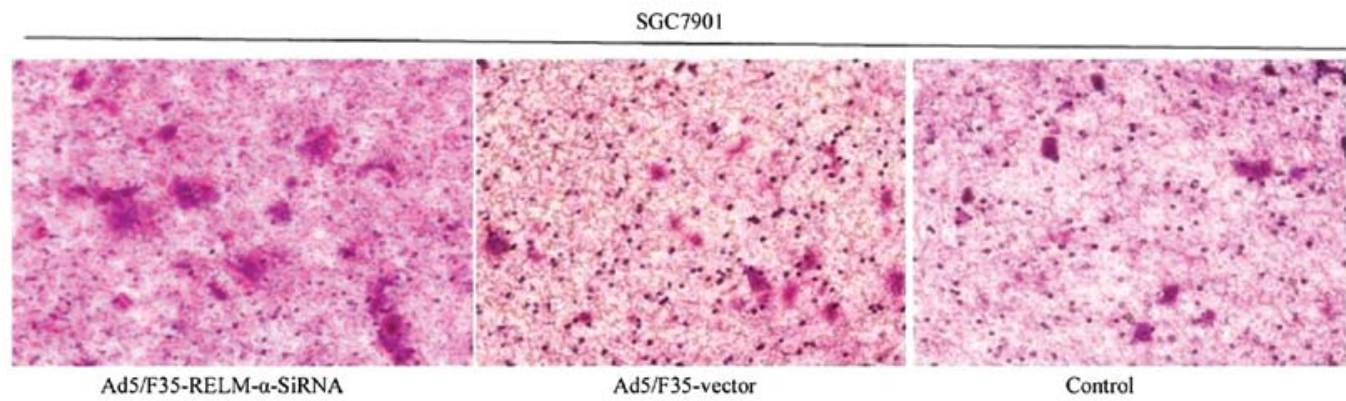

MKN45
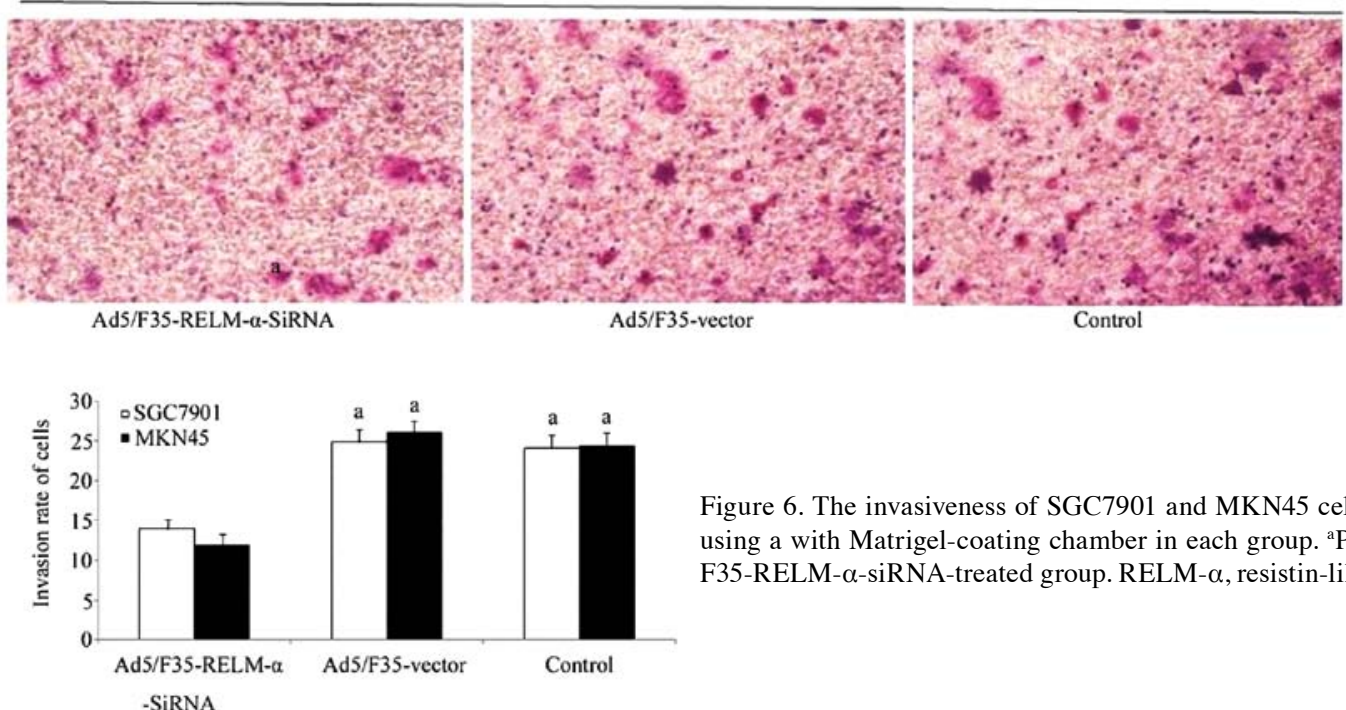

Figure 6. The invasiveness of SGC7901 and MKN45 cells was determined using a with Matrigel-coating chamber in each group. ${ }^{\mathrm{a}} \mathrm{P}<0.01$ vs. the Ad5/ F35-RELM- $\alpha$-siRNA-treated group. RELM- $\alpha$, resistin-like molecule- $\alpha$. 


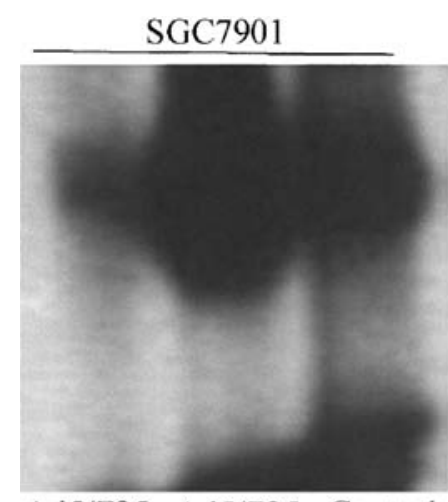

Ad5/F35- Ad5/F35- Control

RELM- $\alpha$ - vector

SiRNA

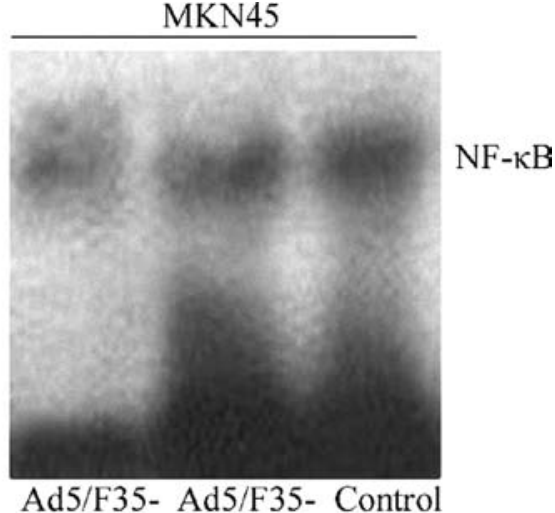

RELM- $\alpha$ - vector

SiRNA

Figure 7. NF- $\kappa B$ activation in the gastric cancer cells was investigated in each group. RELM- $\alpha$, resistin-like molecule- $\alpha$.

A

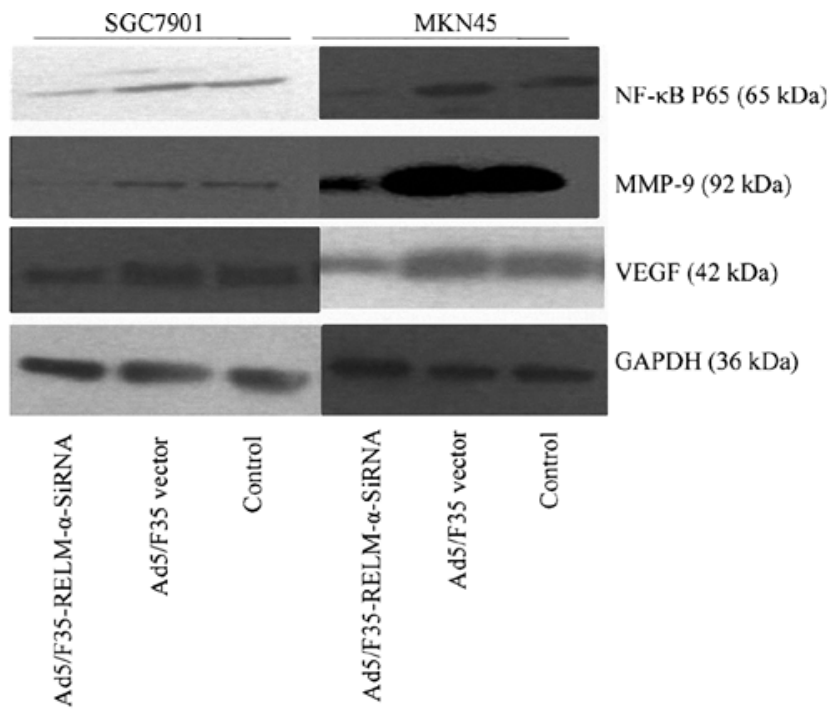

$\mathrm{C}$

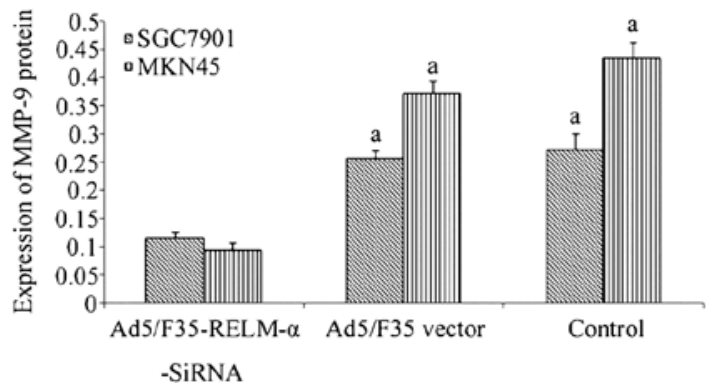

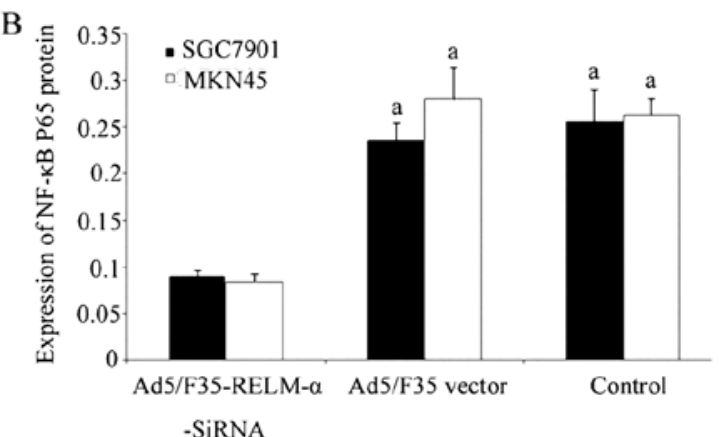

-SiRNA
D

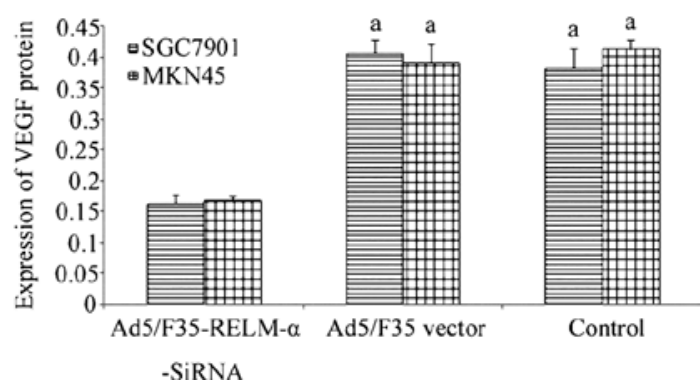

Figure 8. The effective mechanisms of RELM- $\alpha$ silencing involved in cell metastasis were investigated by western blot analysis. (A) The expression levels of (B) NF- $\mathrm{BB}$ p65, (C) MMP-9 and (D) VEGF were investigated in the SGC7901 and MKN45 cells incubated with control, Ad5/F35-vector, Ad5/F35-RELM- $\alpha$ siRNA, respectively. ${ }^{a} \mathrm{P}<0.01$ vs. the Ad5/F35-RELM- $\alpha$-siRNA-treated group. RELM- $\alpha$, resistin-like molecule- $\alpha$.

$24 \mathrm{~h}$, the NF- $\mathrm{BB}-\mathrm{DNA}$ binding activity was decreased when compared with the Ad5/F35 vector-treated and control cells.

The expression level of p65, as the active subunit of NF- $\mathrm{kB}$, was significantly decreased in the Ad5/F35-RELM- $\alpha$-siRNAtreated cells, compared with the level in the Ad5/F35-vector and control cells $(\mathrm{P}<0.01)$. Additionally, the downstream proteins regulated by NF- $\kappa$ B, MMP-9 and VEGF, were also suppressed in the Ad5/F35-RELM- $\alpha$-siRNA-treated cells when compared with the Ad5/F35 vector-treated and the control cells, respectively $(\mathrm{P}<0.01)$ (Fig. 8).

\section{Discussion}

RELM- $\alpha$ belongs to the RELM family of cysteine-rich secretory proteins that share homology with resistin. To date, four members of this family have been identified: RELM- $\alpha$, 
RELM- $\beta$, FIZZ-3 and RELM- $\gamma$ (13). Some studies in animals suggest that the members of the RELM family have important pro-inflammatory and remodeling roles. For example, RELM- $\alpha$ was first discovered in the 'inflammatory zone' of mice with allergic pulmonary inflammation and has also been described as a hypoxia-inducible mitogenic factor implicated in hypoxia-associated vascular remodeling. RELM- $\alpha$ was found to be upregulated in several infectious and inflammatory settings, including infection, allergic airway inflammation and colitis $(14,15)$. Related research demonstrated that RELM- $\alpha$ promotes intestinal APC activation, Th17 cell responses and intestinal inflammation (16). A previous study demonstrated that RELM- $\alpha$ was consistently detectable in the serum, and the expression levels in colonic inflammation (17). In addition, substantial evidence exists that RELM- $\alpha$ regulates pro-inflammatory cytokines (IL-6 and TNF- $\alpha$ ) and activates intracellular pro-inflammatory NF- $\mathrm{NB}$ signaling pathway $(18,19)$.

Angiogenesis is a process of neovascular formation from pre-existing blood vessels, which consists of sequential steps for vascular destabilization, lumen formation and vascular stabilization. Furthermore, angiogenesis is a critical process in the invasion, growth and metastasis of most solid tumors, and induction of angiogenesis represents one of the major hallmarks of cancer (20). Angiogenesis is complex and involves a large number of molecules including VEGF and MMP-9 (21). VEGF is a key mediator in the angiogenesis of cancers through signaling pathways including phosphoinositide 3 kinase (PI3K)/Akt and NF- $\mathrm{NB}$, which stimulate endothelial cells of microvessels to proliferate, migrate and alter their pattern of gene expression (22). The high levels of VEGF in tumors are predictive of high metastatic risk and poor prognosis (23). In the present study, VEGF expression was highly correlated with angiogenesis, malignancy and metastasis of gastric cancer. MVD has been used to evaluate the angiogenic activity of tumors (24). In the present study, the MVD value was significantly increased in the gastric cancer tissues when compared with that in the adjacent normal tissues. This finding suggests that angiogenesis plays an important role in the development of gastric cancer. Furthermore, upregulation of RELM- $\alpha$ was observed in the gastric cancer but not in the normal gastric tissues. In addition, expression of RELM- $\alpha$ was correlation with the expression of VEGF and the MVD in the tissues. In conclusion, our results suggest that RELM- $\alpha$ is a novel independent prognostic marker with functional relevance in gastric cancer, yet its related mechanisms remain unclear.

In the present study, the results demonstrated for the first time that RELM- $\alpha$ was silenced in gastric cancer cell lines by siRNA treatment. We then explored the molecular mechanisms of RELM- $\alpha$, to identify key regulators of the RELM- $\alpha$ mediated effect on gastric cancer.

The activation of $\mathrm{NF}-\kappa \mathrm{B}$ and its signaling pathways are central coordinators of innate and adaptive immune responses. More recently, it has become clear that $\mathrm{NF}-\kappa \mathrm{B}$ also has a critical role in cancer development and progression. Inactivation of NF- $\mathrm{NB}$ decreases tumor multiplicity or size in cancer by downregulating anti-apoptotic gene expression and dampened production of growth-stimulating cytokines (25). Moreover, NF- $\kappa \mathrm{B}$ also regulates tumor angiogenesis and invasiveness (26). NF- $\mathrm{NB}$ p65 is sequestered in the cytoplasm by its inhibitor proteins in cells, and in response to a variety of stimuli, its inhibitor proteins can be phosphorylated resulting in the translocation of cytoplasmic NF- $\mathrm{B}$ p65 into the nucleus, thereby activating the transcription of $\mathrm{NF}-\kappa \mathrm{B}$ target genes (27).

In keeping with this, in the present study, the activation of $\mathrm{NF}-\kappa \mathrm{B}$ was increased in gastric cancer, yet RELM- $\alpha$ silencing decreased its activation. Furthermore, the expression of NF- $\kappa \mathrm{B}$ p65 was decreased in gastric cancer cells by Ad5/F35-RELM$\alpha$-siRNA treatment.

Previous studies have described RELM- $\alpha$ expression in vascular smooth muscle and endothelial cells of the remodeling vasculature in animals (28). The present study also demonstrated that RELM- $\alpha$ expression was positively correlated with angiogenesis of gastric cancers. Based on this result, the study further explored the relationship between RELM- $\alpha$ and VEGF expression.

A recent study suggested that RELM- $\alpha$ upregulated VEGF expression in mouse epithelial cells via an NF- $\kappa \mathrm{B}$-dependent pathway (29) which is in accordance with our present study that found that the VEGF production in cells was significantly attenuated by $\mathrm{NF}-\kappa \mathrm{B}$ signaling pathway inhibitor that was involved in RELM- $\alpha$ silencing in gastric cancer. On the other hand, MMP-9 is a downstream target gene of NF- $\mathrm{NB}$, and has also been found to be upregulated in gastric cancer cells. Furthermore, it has been reported that the expression of MMP-9 is closely correlates with tumor angiogenesis (30). MMP-9 has also been shown to trigger an angiogenic switch during tumor progression by releasing VEGF (31). We found that cells with silenced expression of RELM- $\alpha$ exhibited decreased expression of MMP-9 and VEGF protein when compared to the control cells. Thus, RELM- $\alpha$ is involved in the development of gastric cancer by the NF- $\kappa$ B-MMP-9/VEGF pathway.

In summary, the positive expression of RELM- $\alpha$ in the gastric cancer tissues was related to tumor size, clinical stage and promoted the progression of gastric cancer by angiogenesis. The anti-angiogenesis following RELM- $\alpha$ silencing may be involved in the regulation of the production of angiogenesis factor VEGF and NF- $\mathrm{B}$ signaling pathway activation. Inhibition of RELM- $\alpha$ expression was associated with the inhibition of tumor progression and invasiveness in gastric cancer. Finally, RELM- $\alpha$ targeted gene and protein therapy can be used as an effective molecular targeted therapy for gastric cancer.

\section{References}

1. Zhang D and Fan D: New insights into the mechanisms of gastric cancer multidrug resistance and future perspectives. Future Oncol 6: 527-537, 2010.

2. Hartgrink HH, Jansen EP, van Grieken NC and van de Velde CJ: Gastric cancer. Lancet 374: 477-490, 2009.

3. Santoro R, Carboni F, Lepiane P, Ettorre GM and Santoro E: Clinicopathological features and prognosis of gastric cancer in young European adults. Br J Surg 94: 737-742, 2007.

4. Liu T, Dhanasekaran SM, Jin H, Hu B, Tomlins SA, Chinnaiyan AM and Phan SH: FIZZ1 stimulation of myofibroblast differentiation. Am J Pathol 164: 1315-1326, 2004.

5. Holcomb IN, Kabakoff RC, Chan B, Baker TW, Gurney A, Henzel W, Nelson C, Lowman HB, Wright BD, Skelton NJ, et al: FIZZ1, a novel cysteine-rich secreted protein associated with pulmonary inflammation, defines a new gene family. EMBO J 19: 4046-4055, 2000.

6. Raes G, De Baetselier P, Noël W, Beschin A, Brombacher F and Hassanzadeh Gh G: Differential expression of FIZZ1 and Ym1 in alternatively versus classically activated macrophages. J Leukoc Biol 71: 597-602, 2002. 
7. Stütz AM, Pickart LA, Trifilieff A, Baumruker T, PrieschlStrassmayr E and Woisetschläger M: The Th2 cell cytokines IL-4 and IL-13 regulate found in inflammatory zone 1/resistinlike molecule alpha gene expression by a STAT6 and CCAAT/ enhancer-binding protein-dependent mechanism. J Immunol 170: 1789-1796, 2003.

8. Dong L, Wang SJ, Camoretti-Mercado B, Li HJ, Chen M and Bi WX: FIZZ1 plays a crucial role in early stage airway remodeling of OVA-induced asthma. J Asthma 45: 648-653, 2008.

9. Filbey KJ, Grainger JR, Smith KA, Boon L, van Rooijen N, Harcus Y, Jenkins S, Hewitson JP and Maizels RM: Innate and adaptive type 2 immune cell responses in genetically controlled resistance to intestinal helminth infection. Immunol Cell Biol 92: 436-448, 2014

10. Angelini DJ, Su Q, Kolosova IA, Fan C, Skinner JT, Yamaji-Kegan K, Collector M, Sharkis SJ and Johns RA: Hypoxia-induced mitogenic factor (HIMF/FIZZ1/RELM alpha) recruits bone marrow-derived cells to the murine pulmonary vasculature. PLoS One 5: e11251, 2010.

11. Weidner N, Folkman J, Pozza F, Bevilacqua P, Allred EN, Moore DH, Meli S and Gasparini G: Tumor angiogenesis: A new significant and independent prognostic indicator in early-stage breast carcinoma. J Natl Cancer Inst 84: 1875-1887, 1992.

12. Huang L, Ma J, Tang Y, Chen P, Zhang S, Zhang Y and Yuan YZ: siRNA-based targeting of fractalkine overexpression suppresses inflammation development in a severe acute pancreatitis rat model. Int J Mol Med 30: 514-520, 2012.

13. Steppan CM and Lazar MA: The current biology of resistin. J Intern Med 255: 439-447, 2004.

14. Sun Y, Wang J, Li H and Han X: Found in inflammatory zone 1 induces angiogenesis in murine models of asthma. Lung 186: 375-380, 2008

15. Li X, Yang Y, Fang J and Zhang H: FIZZ1 could enhance the angiogenic ability of rat aortic endothelial cells. Int J Clin Exp Pathol 6: 1847-1853, 2013.

16. Osborne LC, Joyce KL, Alenghat T, Sonnenberg GF, Giacomin PR, Du Y, Bergstrom KS, Vallance BA and Nair MG: Resistin-like molecule $\alpha$ promotes pathogenic Th17 cell responses and bacterial-induced intestinal inflammation. J Immunol 190 2292-2300, 2013.

17. Yamaji-Kegan K, Su Q, Angelini DJ, Champion HC and Johns RA: Hypoxia-induced mitogenic factor has proangiogenic and proinflammatory effects in the lung via VEGF and VEGF receptor-2. Am J Physiol Lung Cell Mol Physiol 291: L1159-L1168, 2006.

18. Munitz A, Waddell A, Seidu L, Cole ET, Ahrens R, Hogan SP and Rothenberg ME: Resistin-like molecule alpha enhances myeloid cell activation and promotes colitis. J Allergy Clin Immunol 122 1200.e1-1207.e1, 2008.

19. Munitz A, Seidu L, Cole ET, Ahrens R, Hogan SP and Rothenberg ME: Resistin-like molecule alpha decreases glucose tolerance during intestinal inflammation. J Immunol 182 2357-2363, 2009.
20. Suzuki S, Dobashi Y, Hatakeyama Y, Tajiri R, Fujimura T, Heldin $\mathrm{CH}$ and Ooi A: Clinicopathological significance of platelet-derived growth factor (PDGF)-B and vascular endothelial growth factor-A expression, PDGF receptor- $\beta$ phosphorylation, and microvessel density in gastric cancer. BMC Cancer 10: 659, 2010.

21. Sia D, Alsinet $C$, Newell $P$ and Villanueva A: VEGF signaling in cancer treatment. Curr Pharm Des 20: 2834-2842, 2014.

22. Abid MR, Schoots IG, Spokes KC, Wu SQ, Mawhinney C and Aird WC: Vascular endothelial growth factor-mediated induction of manganese superoxide dismutase occurs through redox-dependent regulation of forkhead and IkappaB/NF-kappaB. J Biol Chem 279: 44030-44038, 2004.

23. Yu YF, Zhang Y, Shen N, Zhang RY and Lu XQ: Effect of VEGF, P53 and telomerase on angiogenesis of gastric carcinoma tissue. Asian Pac J Trop Med 7: 293-296, 2014.

24. Vermeulen PB, Gasparini G, Fox SB, Toi M, Martin L, McCulloch P, Pezzella F, Viale G, Weidner N, Harris AL, et al: Quantification of angiogenesis in solid human tumours: An international consensus on the methodology and criteria of evaluation. Eur J Cancer 32A: 2474-2484, 1996.

25. Pikarsky E, Porat RM, Stein I, Abramovitch R, Amit S, Kasem S, Gutkovich-Pyest E, Urieli-Shoval S, Galun E and Ben-Neriah Y: NF-kappaB functions as a tumour promoter in inflammationassociated cancer. Nature 431: 461-466, 2004.

26. Karin M and Greten FR: NF-kappaB: Linking inflammation and immunity to cancer development and progression. Nat Rev Immunol 5: 749-759, 2005.

27. Yin Y, Si X, Gao Y, Gao L and Wang J: The nuclear factor- $\kappa \mathrm{B}$ correlates with increased expression of interleukin- 6 and promotes progression of gastric carcinoma. Oncol Rep 29: 34-38, 2013.

28. Teng X, Li D, Champion HC and Johns RA: FIZZ1/RELMalpha, a novel hypoxia-induced mitogenic factor in lung with vasoconstrictive and angiogenic properties. Circ Res 92: 1065-1067, 2003.

29. Tong Q, Zheng L, Lin L, Li B, Wang D, Huang C and Li D: VEGF is upregulated by hypoxia-induced mitogenic factor via the PI-3K/Akt-NF-kappaB signaling pathway. Respir Res 7: 37, 2006.

30. Yan C, Wang H, Aggarwal B and Boyd DD: A novel homologous recombination system to study $92 \mathrm{kDa}$ type IV collagenase transcription demonstrates that the NF-kappaB motif drives the transition from a repressed to an activated state of gene expression. FASEB J 18: 540-541, 2004.

31. Bergers G, Brekken R, McMahon G, Vu TH, Itoh T, Tamaki K, Tanzawa K, Thorpe P, Itohara S, Werb Z, et al: Matrix metalloproteinase- 9 triggers the angiogenic switch during carcinogenesis. Nat Cell Biol 2: 737-744, 2000. 